\title{
Influência da Época de Colheita e da Estocagem na Composição Química da Biomassa Florestal
}

\author{
Martha Andreia Brand ${ }^{1}$, Graciela Inês Bolzon de Muñiz ${ }^{2}$ \\ ${ }^{1}$ Departamento de Engenharia Florestal, Universidade do Estado de Santa Catarina - UDESC \\ ${ }^{2}$ Departamento de Engenharia e Tecnologia Florestal, Universidade Federal do Paraná - UFPR
}

\begin{abstract}
RESUMO
Foi determinada a variação da composição química da madeira com casca em função da época de colheita e do tempo de estocagem. O experimento foi em Lages/SC. Toras com casca de Pinus taeda L. e Eucalyptus dunnii Maiden foram coletadas após a colheita e com dois, quatro e seis meses de armazenamento. Foram avaliados: a solubilidade da madeira em água, o hidróxido de sódio e álcool-tolueno, e o teor de cinzas. A composição química da madeira com casca variou em função da época de colheita das árvores. Nas épocas de primavera e verão, foram obtidas as maiores quantidades de extrativos e teor de cinzas. O tempo de estocagem causou variações na composição química da biomassa florestal. Ocorreram alterações em função da oxidação e da transformação dos extrativos, resultando no aumento da solubilidade em água e álcool tolueno. As variações na composição química, isoladamente, não contribuíram para a melhoria da qualidade energética da biomassa.
\end{abstract}

Palavras-chave: estocagem, energia de biomassa, química da madeira.

\section{Influence of Harvest Season and Storage Time on the Chemical Composition of Forest Biomass}

\begin{abstract}
This study determined the chemical composition variation of forest biomass according to harvest season and storage time. The experiment was carried out in Lages, State of Santa Catarina. Logs with bark of Pinus taeda L. and Eucalyptus dunnii Maiden were collected after harvest with two, four and six months of storage time. Solubility of wood in water, sodium hydroxide, toluene and alcohol and ash contents were evaluated. The chemical composition of wood with bark varied according to the harvest season of the trees. The highest values of extractives and ash content were obtained in summer and spring. The storage time caused variations in the chemical composition of forest biomass. Changes caused by the oxidation and transformation of extractives have occurred, resulting in increased solubility in water and alcohol toluene. Variations in the chemical composition alone did not contribute to the improvement of the biomass energetic quality.
\end{abstract}

Keywords: storage, wood fuel, chemical composition. 


\section{INTRODUÇÃO}

A composição química da parede celular da madeira é basicamente constituída de celulose, lignina e polioses. Além destas, estão presentes os componentes acidentais, orgânicos e inorgânicos, que não participam da formação da parede celular e estão localizados principalmente no lume das células. Dentre os componentes acidentais, os orgânicos são denominados extrativos, por serem extraídos com solventes orgânicos e neutros, e os inorgânicos, denominados cinzas, por se constituírem de sais minerais que participam da nutrição da planta e resultam como resíduo após a combustão completa da biomassa.

Os extrativos são constituídos por uma grande variabilidade de componentes químicos, que representam uma pequena porcentagem da massa seca da madeira. Esses compostos são formados por inúmeros componentes individuais (Browning, 1963; Fengel \& Wegener, 1989; Sjöström, 1993) de natureza hidrofílica ou lipofílica (Sjöström, 1993). Esses compostos estão concentrados nos canais resiníferos e nas células de parênquima (Fengel \& Wegener, 1989).

Basicamente, os extrativos podem ser classificados, segundo sua composição química, em terpenos e terpenoides, graxas e gorduras (compostos alifáticos), e compostos fenólicos (Sjöström, 1993; Klock et al., 2006). Por sua vez, esses compostos químicos se subdividem em inúmeros outros, que estão presentes em quantidade e composição diferenciadas na madeira de Gimnospermas e Angiospermas.

Nas Gimnospermas, os principais extrativos são os ácidos resinosos, monoterpenos voláteis, terpenoides, ésteres de ácidos graxos e esteroides, sendo que a maioria dos polifenóis está concentrada no cerne. Nas Angiospermas, as resinas da madeira são constituídas geralmente de gorduras, ceras e esteroides (Klock et al., 2006).

Além disso, a casca difere da madeira em sua composição química pela presença de polifenóis e suberina, menor porcentagem de polissacarídeos e maior porcentagem de extrativos (Fengel \& Wegenr, 1989).
Com relação aos compostos inorgânicos, o teor de cinzas varia muito em função da espécie de madeira e da posição em que a amostra foi retirada na árvore. Essa propriedade varia também entre árvores do mesmo local de crescimento. E, durante a colheita da biomassa, entre a floresta e a planta de geração de energia, o material pode ser contaminado por meio da adição de pedras e areia (Thörnqvist, 1985).

Portanto, a variabilidade da composição química da madeira tem influência direta sobre sua utilização industrial, nos mais variados setores industriais, desde a indústria de celulose e papel até a aplicação na geração de energia.

Em se tratando de geração de energia, o crescimento do interesse no uso da biomassa para este fim, nos últimos anos, tem revelado a necessidade de estudos ligados ao tratamento da biomassa para a melhoria de sua qualidade energética e também à avaliação do efeito desses tratamentos na composição química da madeira.

O tratamento da biomassa para a geração de energia é composto por várias etapas, sendo uma delas a estocagem. Esta contribui de forma significativa para a redução do teor de umidade, que é a principal propriedade para a melhoria da eficiência e do rendimento energético da biomassa como combustível, pois tem influência direta sobre o poder calorífico (Brand, 2007).

Por sua vez, o desempenho da biomassa é afetado na estocagem pela espécie que dá origem à biomassa; pela época em que a biomassa é colhida; pelo tempo de estocagem, e pela forma e tamanho da biomassa estocada (partículas ou toras, por exemplo). Também os fatores mencionados contribuem para as variações na composição química da madeira (Brand, 2007).

Com relação à espécie que dá origem à biomassa para energia, o comportamento das diversas matériasprimas e dos grupos vegetais (Gimnospermas e Angiospermas dicotiledôneas) é diferenciado durante a estocagem, porque a biomassa florestal usada para a geração de energia inclui muitas espécies e componentes (galhos, folhas, madeira, casca), que diferem muito em relação às suas propriedades físicas e químicas. O papel da estocagem e dos processos de secagem, desde a colheita até a utilização, é muito importante, porém as características diferenciadas 
da biomassa tornam a escolha de uma única forma de estocagem muito difícil (Jirjis, 1995). Além disso, durante o armazenamento, as propriedades do material mudam por causa de processos físicos, químicos e microbiológicos (Thörnqvist, 1985).

Os diferentes teores de lignina na madeira, oriunda de Gimnospermas e Angiospermas, fazem com que o nível de acessibilidade das bactérias e dos fungos à celulose e às polioses seja diferente nesses dois grupos vegetais, resultando em variações na velocidade e na intensidade da biodeterioração (Garstang et al., 2002); esta, por sua vez, tem influência sobre a perda de massa e as alterações no poder calorífico.

Em função dos maiores teores de lignina nas Gimnospermas, o processo de quebra da estrutura desse componente químico com a consequente abertura da estrutura da parede celular, que dá acesso à celulose, é mais difícil nas espécies desse grupo. As Gimnospermas também têm, em média, menos celulose que as Angiospermas e menos pentoses disponíveis. Esses baixos níveis de pentoses impedem mudanças rápidas iniciais no $\mathrm{pH}$ durante a estocagem e a maior lignificação reduz a eficácia das hemicelulases em produzir xilanas (Garstang et al., 2002).

As Angiospermas, em contrapartida, têm maior teor de grupos acetil e graxas, e maior potencialidade de produção de ácido acético, durante a estocagem. As pentoses são constituintes das graxas, que proporcionam às bactérias maior controle da acidificação nas pilhas (Garstang et al., 2002).

Com relação à época em que a biomassa florestal é colhida, Garstang et al. (2002) afirmaram que a época de colheita está relacionada à estação de crescimento das árvores, à dormência e à estocagem de metabólitos. Essas variáveis, por sua vez, afetam as mudanças ocorridas na biomassa florestal durante a estocagem, em razão principalmente das variações de teor de umidade e da suscetibilidade à biodegradação.

Juntamente com o teor de umidade, a quantidade de extrativos presentes na biomassa pode sofrer variações em função da época de colheita. Segundo Garstang et al. (2002), colheitas feitas no verão, incluindo toda a copa da árvore, têm maior conteúdo de umidade e maior quantidade de carboidratos solúveis (Garstang et al., 2002). Além disso, o xilema, não ativo fisiologicamente, tem concentração mais baixa de carboidratos solúveis em água em comparação com as células vivas do câmbio (Nurmi, 1992; Garstang et al., 2002)

A quantidade de extrativos obtidos na madeira é relativamente pequena se comparada à quantidade obtida na casca e na folhagem. Na madeira, os valores obtidos variaram de 3,5 a 5,4\% para coníferas e de 4,4 a 7,5\% para folhosas (Nurmi, 1992). Antes do processo de estocagem, Garstang et al. (2002) encontraram valores entre $0,4 \mathrm{e} 1,94 \%$ para extrativos solúveis em água para madeira de Salix com três anos de idade, colhida no inverno, e entre 0,4 e 2,4\% para madeira de resíduos florestais.

Swan, citado por Fengel \& Wegener (1989), observou variação sazonal na composição dos ácidos graxos totais na madeira de Picea spp., com a presença de ácidos de cadeia curta durante o início de verão e um aumento do ácido linoleico $\left(\mathrm{C}_{18}: 3\right)$ durante a época de inverno. Ao contrário, Ekman et al, citados por Fengel \& Wegener (1989), não encontraram variação nos ácidos graxos na mesma espécie de madeira durante diferentes estações do ano. Estes interpretaram os resultados do estudo anterior como variações em razão da coleta feita em diferentes árvores.

Para o teor de cinzas, não foram encontradas referências com relação à influência da época de colheita sobre a variação dessa propriedade na biomassa.

Com relação ao tempo de estocagem, depois da colheita das árvores, se é empregado o procedimento de estocagem aeróbia, processo que ocorre em uma pilha de madeira, Garstang et al. (2002) afirmam que as alterações químicas evoluem, sendo que os primeiros compostos a serem alterados são os extrativos. Nessas condições, segundo Sjöström (1993), os extrativos lipofílicos (ácidos graxos, glicerídeos, ácidos resinosos, esteróis e esterilesteres) sofrem alteração em sua composição e começam a decrescer, tanto por processos autooxidativos como enzimáticos.

Nos processos auto-oxidativos e enzimáticos, o oxigênio ataca as duplas ligações dos extrativos e inicia uma cadeia de reações que geram radicais livres. Os radicais hidroxílicos são particularmente 
fortes oxidantes. $\mathrm{Na}$ presença de íons de metal de transição, durante a reação, são formados hidroperóxidos que também são decompostos em radicais hidroxílicos. Além disso, as reações de autooxidação são aceleradas pela luz (Sjöström, 1993).

Durante a estocagem de toras de Picea em água do mar, por quatro meses, durante o verão, no sul da Finlândia, Ekmam (não publicado), citado por Sjöström (1993), observou que a quantidade de glicerídeos diminuiu para menos da metade dos valores originais, enquanto que os ácidos graxos aumentaram consideravelmente, aumentando também os ácidos resinosos. Nesse estudo, o autor observou também que os esteróis e estéril-esteres se mantiveram praticamente constantes.

Sjöström (1993) observou que os ácidos resinosos com sistemas de duplas ligações conjugadas do tipo abietano $^{1}$ são oxidados rapidamente. Os ácidos graxos insaturados, tanto livres como insaturados, são também oxidados. A reação do ácido linolênico procede mais rapidamente que o ácido linoleico, que por sua vez é oxidado mais rapidamente que o ácido oleico.

Os ácidos graxos dienoicos e trienoicos são oxidados por certas enzimas, como as liposidases. Como resultado disso, a hidrofilia e a solubilidade em água são aumentadas. Além da oxidação, certas enzimas agem como catalisadoras na hidrólise das graxas (Sjöström, 1993).

Garstang et al. (2002), trabalhando com madeira de Salix e resíduos florestais, na forma de partículas, constataram que o conteúdo de carboidratos solúveis em água no início do experimento de armazenamento apresentou valores entre $0,5 \mathrm{e}$ $1,0 \%$, com valores irregulares, e muita variação nos primeiros 50 dias de estocagem, declinando após esse período para valores uniformes abaixo de $0,5 \%$. Os autores constataram ainda que a liberação dos carboidratos solúveis em água é uniforme nas diferentes profundidades das pilhas.

Garstang et al. (2002) lembram também que as alterações iniciais, ocorridas durante a estocagem,

\footnotetext{
${ }^{1}$ Os mais comuns ácidos resinosos nas Gimnospermas são os terpenoides tricíclicos, que são classificados em tipos pimaranos e abietanos. Os principais ácidos abietanos são: ácido abiético; ácido levopimárico; ácido palústrico; ácidoneoabiético, e ácido dehidroabiético. Este tem um grupo isopropil ou isopropenil na posição C-13. ${ }^{3}$
}

são também em função da fermentação dos açúcares da madeira, produzindo ácidos graxos voláteis, álcool e água, com a liberação de $\mathrm{CO}_{2}$ e calor. $\mathrm{Na}$ ausência de atividades específicas de preservação, a oxidação desses ácidos orgânicos ocorre em vários níveis nas pilhas de madeira.

Entretanto, se os extrativos forem estabilizados pela fermentação para produzir um $\mathrm{pH}$ baixo e estável, então a estocagem terá maior período de estabilidade. Se, subsequentemente, a estocagem é manejada para permitir uma oxidação controlada dos ácidos graxos, então, com o aquecimento endógeno e solar, e a evaporação pelo vento, aliado à mínima retenção de chuva, o material estocado tenderá a ter mínima perda energética, com perda de umidade passiva, durante a estocagem. Os carboidratos solúveis terão uma preservação inicial e energia para o subsequente processo de secagem (Garstang et al., 2002).

Thörnqvist e Johnson et al., apud Jirjis (1995), não observaram alterações significativas na quantidade de lignina ou carboidratos durante períodos de estocagem na madeira contida na biomassa florestal entre 6 e 13 meses, ressaltando ainda que as maiores mudanças foram observadas nos extrativos obtidos por extração em etanol a 95\%. O decréscimo do conteúdo de extrativos observado pelos autores foi superior a $70 \%$ em relação ao originalmente encontrado.

No entanto, durante longos períodos de estocagem, os polissacarídeos da madeira podem ser atacados por micro-organismos (Sjöström, 1993), também conduzindo à formação de extrativos (Jirjis, 1995; Garstang et al., 2002).

Nesse caso, a decomposição da madeira implica em uma mudança na relação entre as proporções dos conteúdos de celulose e lignina. Se o conteúdo de lignina aumenta no material estocado, o que é provável de ocorrer por causa da decomposição por fungos de podridão parda, há também um aumento no poder calorífico superior. Com a decomposição de materiais orgânicos, a porcentagem dos materiais inorgânicos (cinzas) aumenta (Thörnqvist, 1985). Garstang et al. (2002) salientam ainda que qualquer redução significativa na atividade biológica da biomassa sob estocagem, por meio da respiração ou 
fermentação, resultará no aumento da porcentagem de cinzas, sendo este irreversível.

Em estudos realizados por Thörnqvist \& Nylinder e Thörnqvist, citados por Thörnqvist (1985), o teor de cinzas em resíduos florestais reduzidos em partículas, durante a estocagem, apresentou valores médios de 1,3 a 13,1\%. Garstang et al. (2002) constataram que o teor de cinzas de biomassa originária de árvores do gênero Salix, proveniente de rotações curtas, apresentou valores entre 1 e $2 \%$, flutuando drasticamente durante o período de estocagem, provavelmente em função do acaso na coleta das amostras.

No trabalho desenvolvido por Jirjis (2005), o autor concluiu que os teores de cinza de ramos particulados de Salix não tiveram variação significativa durante a estocagem. O valor do material recém-produzido foi de $1,87 \%$ e, após dois e três meses de estocagem, foram obtidos valores de 1,98 a 2,0\% para pilhas de $3 \mathrm{~m}$ e 1,89 a $2,17 \%$ para pilhas de $6 \mathrm{~m}$.

Thörnqvist (1986) observou que o teor de cinzas nas partículas de carvalho variou entre 0,9 e 1,5\% antes da estocagem, e entre 1,4 e 1,6\% após nove meses de estocagem. Nos resíduos de colheita particulados, os valores médios variaram entre 1,8 e 2,4\% antes da estocagem, e de 2,8 a 3,3\% após a estocagem.

Com base nas considerações anteriores de que a composição química da biomassa é alterada em função da época de colheita e da realização de estocagem, o objetivo deste trabalho foi determinar a variação da composição química da biomassa florestal, destinada à geração de energia, em função da época de colheita da biomassa florestal e do tempo de estocagem.

\section{MATERIAL E MÉTODOS}

O estudo foi realizado em Lages, Estado de Santa Catarina, entre outubro de 2003 e fevereiro de 2005. A cidade fica situada a $27^{\circ} 30^{\prime}$ de latitude Sul e a $50^{\circ}$ de longitude Oeste, com altitude entre 800 e 900 m. Conforme a classificação climática de Köppen, essa região pertence ao tipo $\mathrm{Cfb}$, caracterizado por verão fresco, não apresentando déficit hídrico (Leite et al., 1973). Os dados meteorológicos do período de estudo são apresentados na Tabela 1.

Foram utilizados como material de estudo toras com casca de Pinus taeda L. e

Tabela 1. Condições climáticas de Lages/SC (outubro de 2003 a fevereiro de 2005)*.

Table 1. Climatic conditions in Lages/SC (october 2003 to february 2005).

\begin{tabular}{|c|c|c|c|c|}
\hline Ano & Mês & Precipitação (mm) & Temperatura $\left({ }^{\circ} \mathbf{C}\right)$ & Umidade relativa (\%) \\
\hline \multirow{3}{*}{2003} & Out. & 119 & 18 & 76 \\
\hline & Nov. & 94 & 19 & 72 \\
\hline & Dez. & 225 & 20 & 79 \\
\hline \multirow{12}{*}{2004} & Jan. & 81 & 21 & 78 \\
\hline & Fev. & 114 & 21 & 76 \\
\hline & Mar. & 144 & 20 & 77 \\
\hline & Abr. & 82 & 19 & 83 \\
\hline & Maio & 103 & 13 & 85 \\
\hline & Jun. & 28 & 13 & 82 \\
\hline & Jul. & 233 & 12 & 84 \\
\hline & Ago. & 52 & 14 & 77 \\
\hline & Set. & 278 & 17 & 82 \\
\hline & Out. & 162 & 17 & 75 \\
\hline & Nov. & 104 & 19 & 76 \\
\hline & Dez. & 136 & 20 & 76 \\
\hline \multirow{2}{*}{2005} & Jan. & 147 & 22 & 76 \\
\hline & Fev. & 47 & 22 & 75 \\
\hline
\end{tabular}

Fonte: EPAGRI (2006). ${ }^{*} \mathrm{~A}$ precipitação total do ano de 2004 foi de $1517 \mathrm{~mm}$ e os valores médios de temperatura e umidade relativa foram $17{ }^{\circ} \mathrm{C}$ e $79 \%$, respectivamente. Os dados apresentados refletem as condições climáticas de anos típicos na região. 
Eucalyptus dunnii Maiden, com diâmetros variados ${ }^{2}$ e comprimento médio de $2,4 \mathrm{~m}$. Cada material foi estocado, separadamente, em pilhas $(6 \mathrm{~m}$ de comprimento $\times 2,5 \mathrm{~m}$ de largura $\times 2,5 \mathrm{~m}$ de altura). Foram analisados quatro lotes de cada material, que permaneceram sob estocagem durante seis meses, com coletas no material recém-colhido, com dois, quatro e seis meses, com estocagem em diferentes épocas do ano. As épocas de estocagem foram de outubro a maio (Lote 1); janeiro a agosto (Lote 2); maio a novembro (Lote 3 ), e agosto a fevereiro (Lote 4).

As amostras foram coletadas na base, no meio e no topo das pilhas. Sem haver remoção da casca, as toras foram transformadas em cavacos, utilizados na determinação das propriedades químicas (TAPPI, 1994d, e).

Considerando-se os seguintes aspectos: a extração da madeira em água fria remove componentes, como compostos inorgânicos, taninos, gomas, açúcares e materiais coloridos; a água quente remove além desses compostos, o amido; a extração em álcool tolueno remove substâncias, como ceras, graxas, resinas, fitoesteróis, hidrocarbonetos não voláteis, carboidratos de baixa massa molecular e outras substâncias solúveis em água (ABNT, 2000, 2002), estas análises foram escolhidas para verificar se a composição química extracelular da madeira era alterada em função da época de colheita e do tempo de estocagem.

Na medida em que a análise da literatura indicou que os componentes extraíveis por esses métodos são os que sofrem alterações quantitativas durante as diferentes épocas de colheita e os tempos de estocagem, mostra-se, dessa forma, a influência dessas variáveis sobre a variação da composição química da biomassa florestal destinada à geração de energia.

Em termos de época de colheita, a variação da solubilidade da madeira em água indica possíveis alterações metabólicas da árvore em diferentes épocas do ano. Essa informação é importante para

\footnotetext{
${ }^{2}$ Os diâmetros das toras variaram de 8 a mais de $30 \mathrm{~cm}$, pois o material de estudo foi constituído de madeira destinada à geração de energia (toras finas) e toras descartadas em processos industriais (toras grossas), sendo que essa variável não foi controlada no estudo.
}

o uso da biomassa na geração de energia, pois afeta o potencial energético do combustível por meio do aumento do poder calorífico superior, com o aumento de carboidratos e metabólitos, e o aumento da produção de resíduos após a queima pelo aumento do teor de cinzas.

Em termos de tempo de estocagem, as variações nas porcentagens de ácidos graxos, glicerídeos, ácidos resinosos, esteróis e esteril-esteres, pela sua diminuição ou aumento, indicam o início do processo de oxidação e biodegradação da madeira; estas também afetam o potencial energético da biomassa, pois carboidratos aumentam o poder calorífico da madeira, enquanto a perda de ácidos graxos ou ácidos resinosos pode diminuir o potencial energético da biomassa.

Já a solubilidade da madeira a quente em hidróxido de sódio a $1 \%$ indica a remoção de extrativos e carboidratos de baixa massa molecular, que consistem basicamente em algumas polioses (hemiceluloses) e celulose degradada, indicando o grau de degradação causada por fungos ou degradação por calor, luz, oxidação, etc (ABNT, 2001).

Essa análise, juntamente com a solubilidade da madeira em álcool tolueno, é importante principalmente para a avaliação da variação da composição química ao longo do tempo de estocagem, indicando a ocorrência de processos de degradação química (oxidativas) e enzimática (biodegradação por fungos e bactérias).

Dessa forma, a composição química quantitativa da madeira foi avaliada por meio da determinação da solubilidade da madeira em água fria e quente; da solubilidade a quente em hidróxido de sódio a $1 \%$, e em álcool tolueno e teor de cinzas. Essas propriedades foram analisadas segundo as normas TAPPI T 207; TAPPI 212, NBR 14853 e TAPPI 211, respectivamente (TAPPI, 1994a, b, c; ABNT, 2002).

O tratamento estatístico foi feito por meio do teste $\mathrm{F}$ para verificação de variação significativa $e$ a confirmação da variação, pelo Teste de média de Tukey $(\mathrm{p}>0,05)$, para cada propriedade avaliada, tanto para a época de colheita da biomassa, quanto para o tempo de estocagem. 


\section{RESULTADOS E DISCUSSÕES}

\subsection{Quanto à época de colheita da biomassa florestal}

Os resultados obtidos para as variações da composição química da biomassa florestal em função da época de colheita podem ser visualizados na Tabela 2.

Quando analisadas as espécies separadamente (Pinus e Eucalyptus), a época de colheita da madeira apresentou influência sobre as propriedades químicas da biomassa analisada, indicando que a composição e a quantidade dos extrativos (componentes inorgânicos, taninos, gomas, açúcares, compostos que dão cor à madeira e o amido) se alteraram (Tabela 2). Os maiores valores foram observados no verão para Pinus e, na primavera, para Eucalyptus, concordando com Garstang et al. (2002) e Fengel \& Wegener (1989).

O Eucalyptus dunnii Maiden apresentou maior quantidade de metabólitos e substâncias extraíveis que o Pinus taeda, conforme indicado por Nurmi (1992), e teve maiores valores na primavera e no final do inverno, com diferenças significativas entre as épocas de verão e outono.
Já o Pinus taeda L. apresentou maior quantidade de metabólitos no verão, com diferenças significativas principalmente entre os extrativos registrados no verão (janeiro) e as outras épocas do ano, com exceção dos extrativos solúveis em água fria, em que os valores observados no verão são similares aos observados no outono.

Garstang et al. (2002) concluíram em seus trabalhos que colheitas feitas no verão conferem à biomassa maior quantidade de carboidratos solúveis, tendência essa que também foi observada neste trabalho para Pinus.

O teor de cinzas apresentou as mesmas tendências dos extrativos, para ambas as espécies avaliadas.

Considerando-se o uso da biomassa para a geração de energia e comparando-se os valores de metabólitos e extrativos com os valores de poder calorífico superior, obtidos para as espécies nas diferentes épocas de colheita (Tabela 3), podese afirmar que o Pinus apresentou um padrão de comportamento com maior poder calorífico nas épocas com maior quantidade de extrativos e metabólitos, mas o mesmo não foi observado para o Eucalyptus, que teve comportamento inverso, com menor poder calorífico superior na época com maior quantidade de metabólitos, apesar de não haver

Tabela 2. Valores médios da composição química (\%) da biomassa florestal em função da época de colheita.

Table 2. Chemical composition (\%) of forest biomass in relation to the harvest period.

\begin{tabular}{|c|c|c|c|c|}
\hline Solubilidade em água fria & Out. (2003) & Jan. (2004) & Maio (2004) & Ago. (2004) \\
\hline PCC & $2,14^{\mathrm{b}}$ & $2,17^{\mathrm{a}}$ & $2,50^{\mathrm{ab}}$ & $1,00^{c}$ \\
\hline ECC & $3,65^{\mathrm{a}}$ & $2,70^{\mathrm{b}}$ & $3,41^{\mathrm{a}}$ & $3,48^{\mathrm{a}}$ \\
\hline Média (\%) & $2,90^{\mathrm{a}}$ & $2,71^{\mathrm{a}}$ & $2,96^{\mathrm{a}}$ & $2,24^{\mathrm{a}}$ \\
\hline Solubilidade em água quente & Out. (2003) & Jan. (2004) & Maio (2004) & Ago. (2004) \\
\hline PCC & $3,33^{\mathrm{b}}$ & $4,21^{\mathrm{a}}$ & $2,26^{c}$ & $2,33^{c}$ \\
\hline ECC & $5,34^{\mathrm{a}}$ & $3,54^{\mathrm{c}}$ & $3,73^{c}$ & $4,65^{\mathrm{b}}$ \\
\hline Média (\%) & $4,34^{\mathrm{a}}$ & $3,87^{\mathrm{a}}$ & $3,00^{\mathrm{a}}$ & $3,49^{\mathrm{a}}$ \\
\hline Solubilidade em $\mathrm{NaOH}(\%)$ & Out. (2003) & Jan. (2004) & Maio (2004) & Ago. (2004) \\
\hline PCC & $16,03^{\mathrm{b}}$ & $17,07^{\mathrm{a}}$ & $13,40^{c}$ & $10,46^{\mathrm{d}}$ \\
\hline ECC & $18,17^{\mathrm{a}}$ & $15,48^{c}$ & $15,48^{\mathrm{c}}$ & $16,83^{\mathrm{b}}$ \\
\hline Média (\%) & $17,10^{\mathrm{a}}$ & $16,27^{\mathrm{ab}}$ & $14,44 \mathrm{ab}$ & $13,65^{\mathrm{b}}$ \\
\hline Teor de cinzas (\%) & Out. (2003) & Jan. (2004) & Maio (2004) & Ago. (2004) \\
\hline PCC & $0,41^{\mathrm{c}}$ & $0,56^{\mathrm{a}}$ & $0,48^{\mathrm{b}}$ & $0,35^{\mathrm{d}}$ \\
\hline ECC & $1,01^{\mathrm{a}}$ & $0,57^{d}$ & $0,69^{c}$ & $0,84^{\mathrm{b}}$ \\
\hline Média (\%) & $0,71^{\mathrm{a}}$ & $0,57^{\mathrm{a}}$ & $0,59^{a}$ & $0,59^{a}$ \\
\hline
\end{tabular}

Nota: Médias seguidas da mesma letra, NA LINHA, não diferem significativamente entre si (Tukey $\mathrm{p}>0,05)$. PCC $=$ toras de Pinus taeda L. com casca; ECC = toras de Eucalyptus dunnii Maiden com casca. 
Tabela 3. Poder calorífico superior de toras de Pinus taeda e Eucalyptus dunnii de acordo com a época de colheita

Table 3. Gross calorific value of Pinus taeda and Eucalyptus dunnii logs according to the harvesting season

\begin{tabular}{lcccc}
$\begin{array}{c}\text { Poder calorífico } \\
\text { superior (kcal/kg) }\end{array}$ & Out. (2003) & Jan. (2004) & Maio (2004) & Ago. (2004) \\
\hline PCC & $4796^{\mathrm{ab}}(43,98)$ & $4867^{\mathrm{a}}(60,00)$ & $4766^{\mathrm{b}}(16,0)$ & $4722^{\mathrm{b}}(19,00)$ \\
ECC & $4494^{\mathrm{a}}(32,00)$ & $4571^{\mathrm{a}}(28,0)$ & $4544^{\mathrm{a}}(9,50)$ & $4560^{\mathrm{a}}(43,50)$ \\
Média & & & & \\
\hline
\end{tabular}

Valores seguidos da mesma letra, na linha, não diferem estatisticamente entre si (Tukey p $>0.05$ ). Valores entre parênteses referem-se ao desvio padrão dos valores apresentados. Fonte: Brand et al., 2011.

diferenças significativas entre os valores de poder calorífico.

No entanto, segundo Brand (2010), diferenças nos valores do poder calorífico da biomassa inferiores a $300 \mathrm{kcal} / \mathrm{kg}$ não têm efeito prático nos sistemas de geração de energia. Portanto, a colheita da biomassa em diferentes épocas do ano não terá efeito positivo na melhoria da qualidade da biomassa para geração de energia.

O teor de cinzas é baixo para ambas as espécies, proporcionando pequena quantidade de resíduos após a queima da biomassa.

Quando os resultados obtidos para as duas espécies analisadas foram agrupados (Figuras 1-4), sem a distinção de espécie, não foram observadas variações significativas da época de colheita sobre a quantidade de extrativos solúveis em água fria e quente, e de teor de cinzas, mantendo-se os maiores valores obtidos na primavera e maior homogeneidade, e menor variação entre os valores observados no verão, para todas as análises realizadas.

Tanto os valores obtidos para água fria quanto para água quente estão de acordo com os observados por Nurmi (1992) e foram superiores aos observados por Garstang et al. (2002).

Já para a solubilidade em hidróxido de sódio a $1 \%$, houve variação entre as épocas de colheita, com maiores valores no início da primavera e menores valores no final do inverno.

Considerando-se a composição química da madeira, a melhor época de colheita foi a primavera. Nessa época, a biomassa tem maior quantidade de componentes extrativos, mas somente essa característica, analisada de forma isolada, não contribui para a melhoria da qualidade da biomassa para a geração de energia, pois não ocorre aumento do poder calorífico, com pode ser observado na Tabela 3.

\subsection{Quanto ao tempo de estocagem}

Os resultados das variações da composição química da biomassa ao longo de seis meses de estocagem, dos quatro lotes analisados, podem ser visualizados na Tabela 4 .

Com relação ao tempo de estocagem, para ambas as espécies, durante os dois primeiros meses de estocagem, ocorreram reações de transformação e disponibilização dos extrativos (oxidação, fermentação, reações enzimáticas), indicadas pelo aumento da solubilidade em água fria, quente e álcool tolueno, observadas também por Sjöström (1993) e Garstang et al. (2002).

Essa constatação pode ser feita porque, com dois meses, a porcentagem de solubilizados aumenta em relação aos valores iniciais. Após quatro meses, esses componentes, além de serem transformados e disponibilizados, são também perdidos, por volatilização ou lixiviação, contribuindo para a diminuição dos valores, em relação aos observados anteriormente.

No entanto, as variações observadas neste trabalho foram inferiores aos 70\% mencionados por Johnson et al., citados por Jirjis (1995), que avaliaram as diferenças na composição de quatro espécies madeiráveis e seis espécies herbáceas, durante períodos de estocagem que variaram de 26 a 52 semanas.

Além disso, como foi realizada análise da madeira com casca, o tempo de estocagem pode ter contribuído para a diminuição da proporção de casca em relação à madeira, como observado por Nurmi (1995), quando este avaliou a variação do poder calorífico em biomassa estocada. A diminuição da proporção de casca afeta a quantidade de extrativos, uma vez que aquela tem maior proporção de extrativos em relação à madeira, de forma a diminuir 


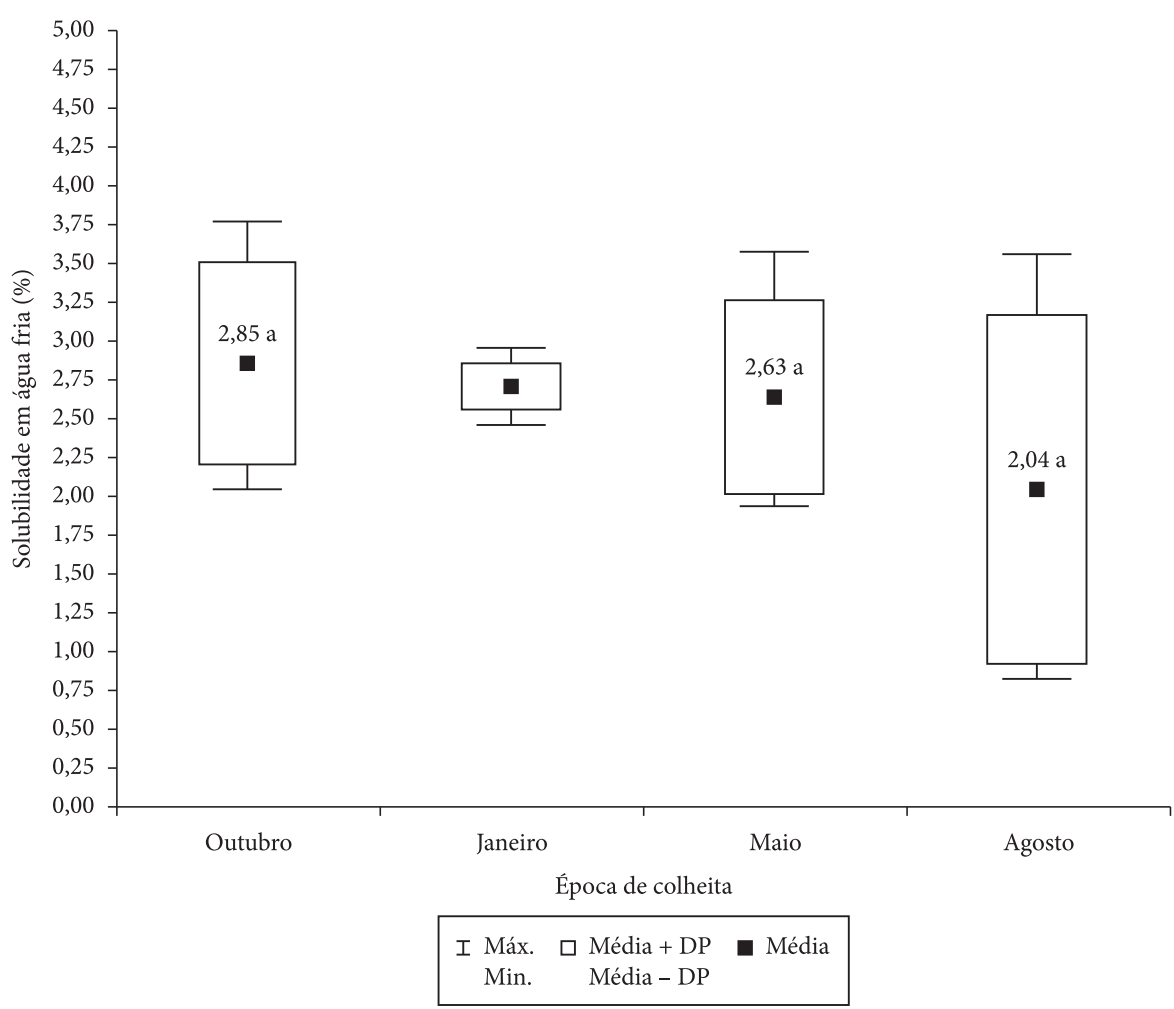

Figura 1. Variação da solubilidade da biomassa florestal em água fria em função da época de colheita (2003/2004). Figure 1. Variation of solubility of forest biomass in cold water in relation to the harvest period (2003/2004).

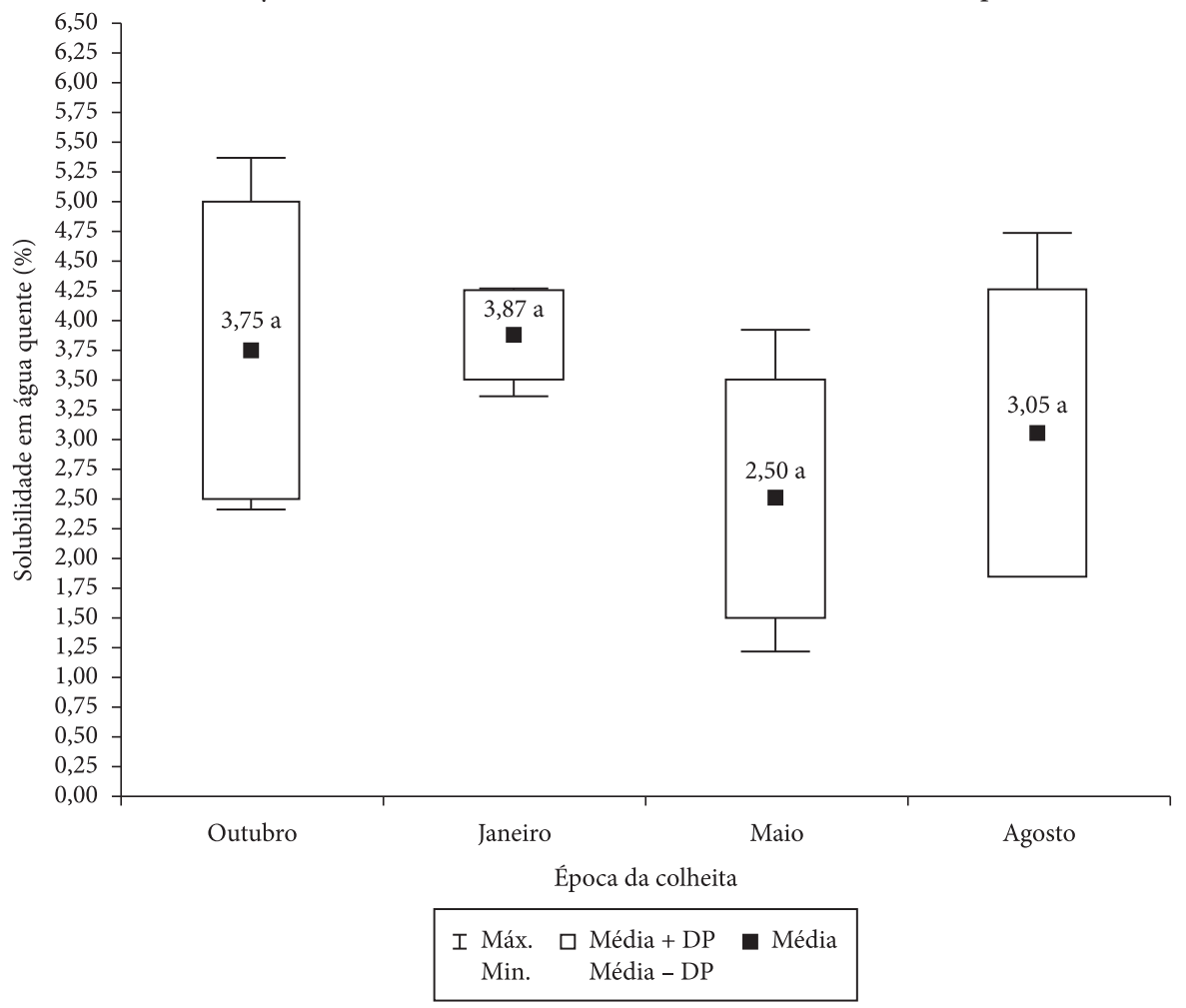

Figura 2. Variação da solubilidade da biomassa florestal em água quente em função da época de colheita (2003/2004). Figure 2. Variation of solubility of forest biomass in hot water in relation to the harvest period (2003/2004). 


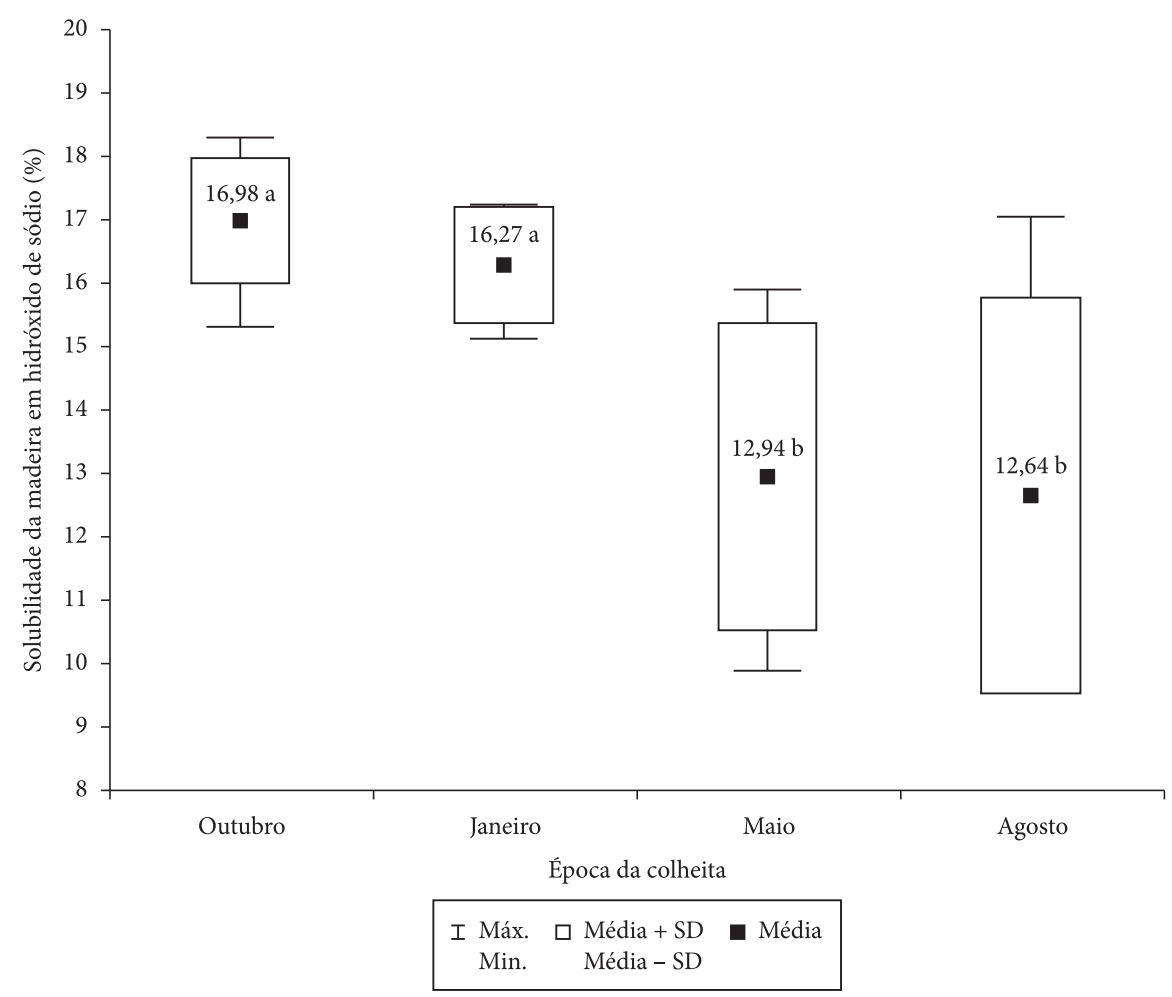

Figura 3. Variação da solubilidade da biomassa florestal em hidróxido de sódio em função da época de colheita (2003/2004).

Figure 3. Variation of solubility of forest biomass in sodium hydroxide in relation to the harvest period (2003/2004).

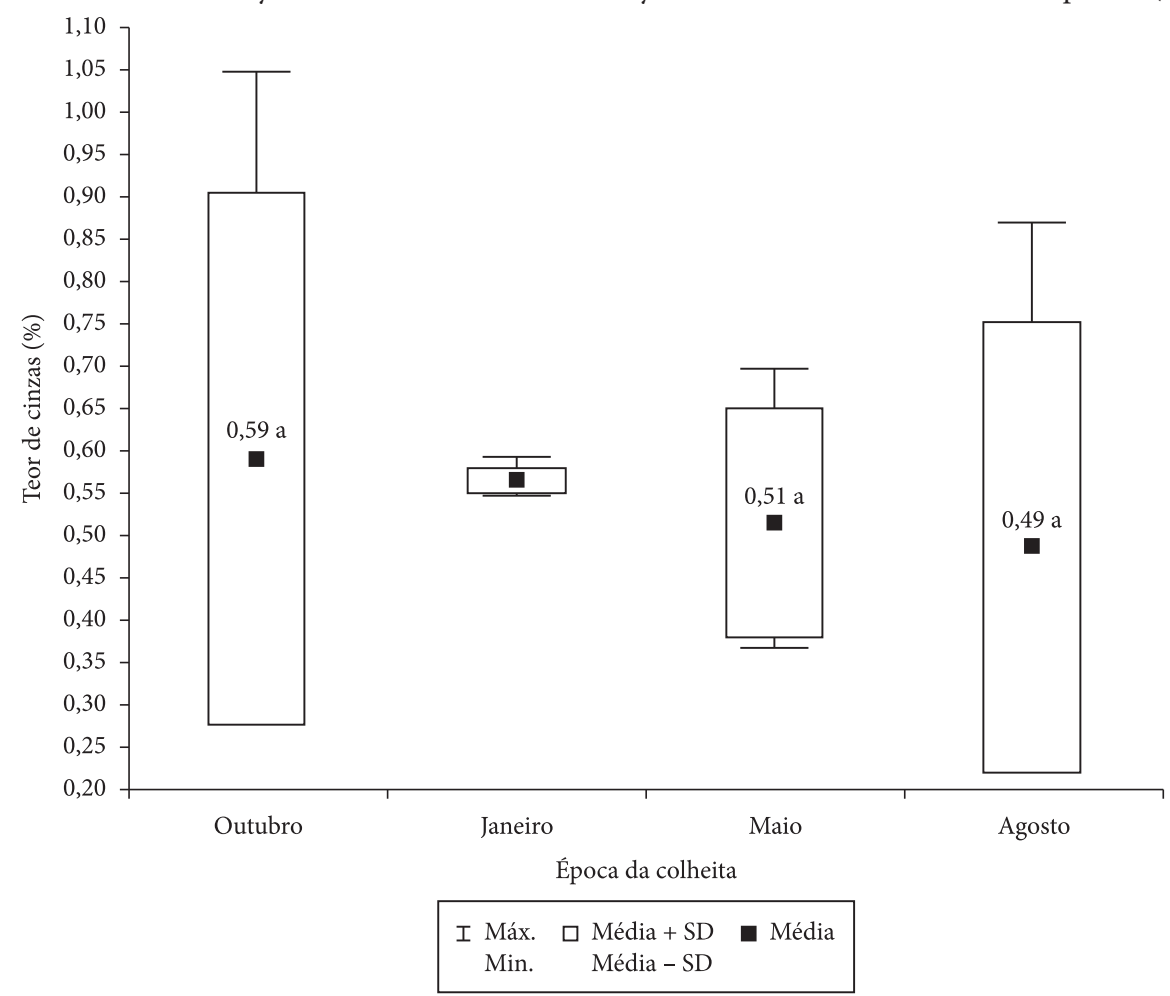

Figura 4. Variação do teor de cinzas da biomassa florestal em função da época de colheita (2003/2004). Figure 4. Variation of ash content of forest biomass in relation to the harvest period (2003/2004). 
Tabela 4. Variação das propriedades químicas da biomassa florestal em função do tempo de estocagem.

Table 4. Change in chemical properties of forest biomass as a function of storage time.

\begin{tabular}{|c|c|c|}
\hline Tempo de estocagem (meses) & Pinus com casca & Eucalyptus com casca \\
\hline \multicolumn{3}{|l|}{ Solubilidade em água fria (\%) } \\
\hline Recém-coletado & $2,09^{b}$ & $3,31^{\mathrm{ab}}$ \\
\hline 2 meses & $3,46^{\mathrm{a}}$ & $3,72^{\mathrm{a}}$ \\
\hline 4 meses & $1,86^{\mathrm{b}}$ & $2,23^{\mathrm{bc}}$ \\
\hline 6 Meses & $1,62^{\mathrm{b}}$ & $1,76^{\mathrm{c}}$ \\
\hline \multicolumn{3}{|l|}{ Solubilidade em água quente (\%) } \\
\hline Recém-coletado & $3,03^{\mathrm{ab}}$ & $4,31^{\mathrm{a}}$ \\
\hline 2 meses & $4,03^{\mathrm{a}}$ & $4,25^{\mathrm{a}}$ \\
\hline 4 meses & $2,72^{\mathrm{ab}}$ & $3,39^{\mathrm{a}}$ \\
\hline 6 Meses & $2,15^{b}$ & $2,93^{\mathrm{a}}$ \\
\hline \multicolumn{3}{|l|}{ Solubilidade em hidróxido de sódio (\%) } \\
\hline Recém-coletado & $14,24^{\mathrm{a}}$ & $16,49^{\mathrm{a}}$ \\
\hline 2 meses & $11,72^{\mathrm{a}}$ & $13,76^{\mathrm{ab}}$ \\
\hline 4 meses & $11,87^{a}$ & $13,08^{\mathrm{b}}$ \\
\hline 6 Meses & $11,73^{\mathrm{a}}$ & $12,67^{\mathrm{b}}$ \\
\hline \multicolumn{3}{|l|}{ Solubilidade em álcool tolueno (\%) } \\
\hline Recém-coletado & $4,47^{\mathrm{b}}$ & $3,04^{\mathrm{b}}$ \\
\hline 2 meses & $5,54^{\mathrm{a}}$ & $4,08^{\mathrm{a}}$ \\
\hline 4 meses & $6,15^{\mathrm{a}}$ & $2,71^{\mathrm{b}}$ \\
\hline 6 Meses & $2,11^{\mathrm{c}}$ & $3,33^{\mathrm{b}}$ \\
\hline \multicolumn{3}{|l|}{ Teor de cinzas $(\%)$} \\
\hline Recém-coletado & $0,45^{\mathrm{a}}$ & $0,78^{\mathrm{ab}}$ \\
\hline 2 meses & $0,41^{\mathrm{a}}$ & $1,02^{\mathrm{a}}$ \\
\hline 4 meses & $0,39^{\mathrm{a}}$ & $0,61^{\mathrm{b}}$ \\
\hline 6 Meses & $0,43^{\mathrm{a}}$ & $0,97^{\mathrm{a}}$ \\
\hline
\end{tabular}

Nota: Médias seguidas da mesma letra, na coluna, não diferem significativamente entre si (Tukey p >0,05).

a quantidade de solubilizados no material com maior tempo de estocagem.

Segundo Fengel \& Wegener (1989), a composição química da casca difere da madeira pela presença de polifenóis e suberina, pela baixa porcentagem de polissacarídeos e alta porcentagem de extrativos. Os extrativos podem variar de 18,3 a $27,5 \%$ na casca de Pinus taeda, em função do tipo de solventes utilizados.

Os processos de transformação e disponibilização (processos químicos), no início do período de estocagem, seguidos da perda por processos físicos ocorridos na solubilidade em água fria se repetiram para a água quente e o álcool tolueno. Nesse aspecto, Garstang et al. (2002) também observaram valores irregulares na solubilidade dos extrativos solúveis em água nos primeiros 50 dias de estocagem, com queda de até $50 \%$ nos valores, após esse período, ou manutenção dos valores iniciais.
Além dessa constatação, o fenômeno de aumento da solubilidade da madeira em água e álcool tolueno, no início do período de estocagem, é explicado por Sjöström (1993) como sendo resultado da oxidação dos ácidos graxos dienoicos e trienoicos, por certas enzimas (liposidases), que tem como consequência o aumento da hidrofilia e da solubilidade em água.

Essa afirmação é possível, pois a solução de álcali aquecida $(\mathrm{NaOH}$ a $1 \%)$ extrai carboidratos de baixo peso molecular, constituídos basicamente de polioses e celulose degradada. A solubilidade da madeira pode indicar o grau de degradação por fungos, calor, luz, oxidação, entre outros, sendo que, na madeira degradada, a porcentagem de materiais solúveis em álcali aumenta (TAPPI, 1994c). No entanto, nos resultados obtidos, a porcentagem de materiais solúveis em hidróxido de sódio diminuiu, indicando que houve somente perda dos componentes extrativos da madeira, sem degradação dos componentes da 
parede celular por agentes de biodegradação. Neste contexto, para ambas as espécies avaliadas, houve diminuição dos compostos solúveis em hidróxido de sódio, ao longo do tempo de estocagem, em relação aos valores iniciais (testemunha).

Além disso, Johnson et al, apud Jirjis (1995) e Thörnqvist (1986) observaram que, em estocagem com períodos de até nove meses, não houve perdas significativas dos polissacarídeos e da lignina na madeira, concordando com o observado indiretamente neste trabalho.

De forma geral, a composição química da madeira não pode ser utilizada de forma isolada para a determinação do tempo ideal de estocagem pelo seguinte motivo: essas propriedades se relacionam com as demais, como o teor de umidade e o poder calorífico, em maior ou menor intensidade, as quais têm relação mais direta com o tempo de estocagem. Os resultados da variação do poder calorífico superior ao longo de seis meses de estocagem, para essas espécies, apresentados por Brand et al. (2011), indicaram que o tempo de estocagem não alterou o poder calorífico superior de forma significativa, porém teve grande impacto sobre a redução do teor de umidade, melhorando significativamente a qualidade da biomassa para geração de energia.

Além disso, os fatores época, espécie, tamanho e forma da biomassa também têm influência sobre o tempo de estocagem. Dessa forma, as propriedades avaliadas neste trabalho são utilizadas para a análise das variações dos componentes constituintes da parede celular ou que ficam no lúmen das células, os quais, por sua vez, indicam se a biomassa terá variações no comportamento das outras propriedades avaliadas que têm impacto sobre a qualidade da biomassa para geração de energia.

Em razão de não ocorrerem alterações na composição da estrutura celular da madeira, o teor de cinzas não aumentou, como mencionou Garstang et al. (2002), que observaram a tendência linear de aumento do teor de cinzas ao longo do tempo de estocagem, com 27 a $45 \%$ das variações explicadas pelo tempo de estocagem.

Neste trabalho, não houve aumento do teor de cinzas, não havendo diferença significativa para Pinus, sendo que as variações observadas para Eucalyptus podem ser atribuídas ao acaso nas coletas realizadas, como também observou Garstang et al. (2002).

\section{CONCLUSÕES}

\subsection{Quanto à época de colheita}

- A composição química da madeira com casca de Pinus taeda e Eucalyptus dunnii varia em função da época de colheita das árvores;

- O Eucalyptus dunnii Maiden apresentou maior quantidade de metabólitos e substâncias extraíveis que o Pinus taeda;

- Nas épocas de primavera e verão, estações de crescimento das árvores, foram obtidas as maiores quantidades de extrativos e teor de cinzas na madeira com casca;

- A variação na composição química observada em função da época de colheita não teve efeito sobre a variação no poder calorífico superior das espécies avaliadas, não contribuindo para a melhoria da qualidade da biomassa para geração de energia.

\subsection{Quanto ao tempo de estocagem}

- O tempo de estocagem, de zero a seis meses, causou variações na composição química da biomassa florestal;

- Durante o tempo de seis meses de estocagem, houve variações na solubilidade da madeira em: água fria, água quente, álcool tolueno e hidróxido de sódio a $1 \%$, mas não provocou alterações significativas no teor de cinzas;

- Durante os dois primeiros meses de estocagem, ocorrem alterações em função de processos de oxidação e transformação dos extrativos, contribuindo para o aumento da solubilidade da madeira em água e álcool tolueno;

- Até seis meses de estocagem, ocorrem somente alterações nos extrativos, não havendo degradação da parede celular por processos de biodegradação, o que é demonstrado pela redução da solubilidade em hidróxido de sódio ao longo do período de estocagem;

- A qualidade da biomassa para geração de energia não pode ser avaliada somente pela variação da composição química ao longo do tempo de estocagem, devendo-se avaliar a variação do poder calorífico e o teor de umidade durante a estocagem. 


\section{STATUS DA SUBMISSÃO}

Recebido: 21/02/2011

Aceito: 13/02/2012

Resumo publicado online: 17/02/2012

Artigo completo publicado: 31/03/2012

\section{AUTOR(ES) PARA CORRESPONDÊNCIA}

\section{Martha Andreia Brand}

Departamento de Engenharia Florestal, Universidade do Estado de Santa Catarina UDESC,

Av. Luiz de Camões, 2090, Conta Dinheiro, CEP 88520-000, Lages, SC, Brasil e-mail:a2mab@cav.udesc.br

\section{REFERENNCIAS}

Associação Brasileira de Normas Técnicas - ABNT. NBR 14577: pasta celulósica e madeira - determinação do material solúvel em água. Rio de Janeiro: ABNT; 2000.

Associação Brasileira de Normas Técnicas - ABNT. NBR 14853: madeira - determinação do material solúvel em etanol-tolueno e em diclorometano. Rio de Janeiro: ABNT; 2002.

Associação Brasileira de Normas Técnicas - ABNT. NBR 7990: madeira - determinação do material solúvel em hidróxido de sódio a 1\%. Rio de Janeiro: ABNT; 2001.

Brand MA. Energia de Biomassa Florestal. Rio de Janeiro: Interciência; 2010.

Brand MA. Qualidade da biomassa florestal para o uso na geração de energia em função da estocagem [tese]. Curitiba: Universidade Federal do Paraná; 2007.

Brand MA, Muniz GIB, Quirino WF, Brito JO. Storage as a tool to improve wood fuel quality. Biomass and Bioenergy 2011; 35: 2581-2588.

Browning BL. The chemistry of wood. New York; London: John Wiley \& Sons; 1963.

Empresa de Pesquisa Agropecuária e Extensão Rural de Santa Catarina - EPAGRI. Estação meteorológica. Lages: Estação Experimental de Pesquisa Agropecuária de Lages; 2006.

Fengel D, Wegener G. Wood. Chemistry, Ultrastructure, reactions. New York: Gruyter; 1989.

Garstang J, Weekes A, Poulter R, Bartlett D. Identification and characterisation of factors affecting losses in the large-scale, non-ventilated bulkstorage of wood chips and development of best storage practices. 2002.

Jirjis R. Effects of particle size and pile height on storage and fuel quality of comminuted Salix viminalis. Biomass and Bioenergy 2005; 28: 193-201. http://dx.doi. org/10.1016/j.biombioe.2004.08.014

Jirjis R. Storage and drying of wood fuel. Biomass and Bioenergy 1995; 9 (1-5): 181-190.

Klock U, Muñiz GIB, Hernandez JA. Química da Madeira. 3rd ed. Curitiba: Série didática FUPEF; 2006.

Leite NB, Ferreira M, Ramos PG, Gutierrez Neto F. Efeito de geadas sobre diversas espécies/procedências de Eucalyptus spp introduzidas na região de Lages Santa Catarina. IPEF 1973; 7: 101-114.

Nurmi J. Measurement and evaluation of wood fuel. Biomass and Bioenergy 1992; 2 (1-6): 157-171.

Nurmi J. The effect of whole-tree storage on the fuelwood properties of short-rotation Salix crops. Biomass and Bioenergy 1995; 8 (4): 245-249. http:// dx.doi.org/10.1016/0961-9534(95)00032-3

Sjöström E. Wood chemistry. Fundamentals and applications. 2rd ed. Califórnia: Academic Press; 1993.

Technical Association for the Woldwide Pulp, Paper and Converting Industry -TAPPI. TAPPI-207: Water solubility of wood. Atlanta; 1994a.

Technical Association for the Woldwide Pulp, Paper and Converting Industry -TAPPI. TAPPI 211: Ash in wood, pulp, paper and paperboard: combustion at $525^{\circ} \mathrm{C}$. Atlanta; $1994 \mathrm{~b}$.

Technical Association for the Woldwide Pulp, Paper and Converting Industry -TAPPI. TAPPI 212: One percent sodium hydroxide solubility of wood and pulp. Atlanta; 1994c.

Technical Association for the Woldwide Pulp, Paper and Converting Industry -TAPPI. TAPPI 257: Sampling and preparing wood for analysis. Atlanta; 1994d.

Technical Association for the Woldwide Pulp, Paper and Converting Industry -TAPPI. TAPPI 264: Preparation of wood for chemical analysis (Including procedures of removal of extractive and determination of moisture content). Atlanta; 1994e.

Thörnqvist T. Drying and storage of forest residues for energy production. Biomass 1985; 7: 125-134.

Thörnqvist T. Projekt storskalig säsongslagring av trädbraänsle - en sammanfattning av etapp 1. Largescale seasonal storage of tree fuel project - summary of phase 1. Sweden: The Swedish University of Agricultural Sciences; $1986 . \quad$ http://dx.doi.org/10.1016/01444565(85)90038-1 